\title{
Tarefa Investigativa no ensino de derivadas em uma turma de Licenciatura em Matemática
}

\author{
Investigative Task in the teaching of derivatives in a class of \\ Degree in Mathematics
}

\author{
Carlos José Ferreira Soares (iD https://orcid.org/0000-0002-0265-8944 \\ Universidade do Estado do Amazonas \\ cjsoares@uea.edu.br
}

Marli Teresinha Quartieri (iD https://orcid.org/0000-0002-9621-3830

Universidade do Vale do Taquiri - UNIVATES

mtquartieri@univates.br

\section{Resumo}

O presente trabalho teve como objetivo analisar estratégias e conjecturas que os alunos da disciplina de Cálculo I de uma turma de Licenciatura em Matemática elaboram ao utilizarem tarefas investigativas envolvendo derivadas. Como base teórica, este estudo esteve pautado em Ponte, Brocardo e Oliveira (2016), Magalhães e Varizo (2016) em relação aos fundamentos da Investigação Matemática. A metodologia da pesquisa foi qualitativa, assistida pela observação participante e pela análise descritiva. Em especial, foi enfocado taxa de variação, máximos e mínimos de funções. Os resultados enfatizam que o desenvolvimento de tarefas investigativas em sala de aula, contribui para que o aluno seja ativo na busca da construção de conhecimento matemático. Para a formulação de conjecturas utilizaram diversas estratégias: simulações por meio da construção de quadros, desenhos, modelagem de funções e uso do Excel. Pode-se inferir que esta metodologia tem potencial para auxiliar o professor a desenvolver aulas mais dinâmicas e oferecer possibilidades de 0 aluno assumir 0 protagonismo na sua formação educacional.

Palavras-chave: Investigação Matemática. Derivada. Ensino Superior.

\section{Abstract}

The present work had as objective to analyze strategies and conjectures that the students of the subject of Calculus I of a class of Degree in Mathematics elaborate when using investigative tasks involving derivatives. As a theoretical basis, this study was based on Ponte, Brocardo and Oliveira (2016), Magalhães and Varizo (2016) in relation to the foundations of Mathematical Research. The 
research methodology was qualitative, assisted by participant observation and descriptive analysis. In particular, the rate of change, function maximums and minimums were focused. The results emphasize that the development of investigative tasks in the classroom, contributes for the student to be active in the search for the construction of mathematical knowledge. For the formulation of conjectures, they used several strategies: simulations through the construction of charts, drawings, function modeling and use of Excel. It can be concluded that this methodology has the potential to help the professor to develop more dynamic classes and offer possibilities for the student to take the lead in his educational training.

Key words: Mathematical Investigation. Derivative. University Education.

\section{Introdução}

Os processos de ensino e de aprendizagem de matemática estão sofrendo mudanças nos últimos anos devido à preocupação dos pesquisadores em investigar novas alternativas de produção de conhecimentos matemáticos que despertem nos alunos motivação pelo estudo. De acordo com Santos (2008), alguns alunos têm medo desta disciplina, porque para eles a matemática é muito difícil de entender e também chata e por isso alguns alunos acabam tendo aversão à matemática.

Estes educandos relacionam geralmente a matemática com tarefas exaustivas e apresentam dificuldades de aprendizagem. Diante de tal contexto, professores da disciplina produzem reflexões acerca das transformações que o ensino vem passando em prol do desenvolvimento da construção de conhecimentos de forma contextualizada e autônoma. Entretanto, segundo Krueger (2009), apesar do otimismo dessa realidade os docentes sabem que podem enfrentar obstáculos, visto que a escola ainda apresenta conhecimentos matemáticos distante da realidade dos alunos e pautados no ensino tradicional, valorização do treino, memorização e repetição, sem conexão com a vivência do aluno.

Segundo os PCNs (BRASIL, 1998) o ensino de matemática deve promover o desenvolvimento do raciocínio do aluno, mediante a exploração de metodologia que priorize a aplicação de estratégias dinâmicas, estimulando a reflexão crítica do pensamento matemático. Nessa mesma linha argumentativa, a Base Nacional Comum Curricular (BNCC) destaca que "[...] desenvolver o raciocínio lógico, o espírito de investigação e a capacidade de produzir argumentos convincentes, recorrendo aos conhecimentos matemáticos para compreender e atuar no mundo [...]" (BRASIL, 2018, p. 265) são fundamentais para a construção autônoma de conhecimentos matemáticos.

Pautado nesses argumentos, o presente trabalho foi desenvolvido a partir do objetivo de analisar estratégias e conjecturas elaboradas pelos alunos da disciplina de Cálculo I, do curso de Licenciatura em Matemática, de uma Instituição do norte do Brasil, ao utilizarem tarefas investigativas envolvendo derivadas. Como recursos metodológicos, fundamenta-se na abordagem qualitativa, observação participante e análise descritiva. 


\title{
O estudo das derivadas
}

O ensino de derivadas é um tema explorado em pesquisas científicas devido suas diversas aplicações em áreas como Matemática, Física, Química, Engenharias, Economia, dentre outras. Gonçalves (2012, p. 32) afirma que:

\begin{abstract}
O conceito de derivada é considerado um dos conceitos fundamentais do Cálculo. Por isso, seu estudo está presente no currículo de diversos cursos superiores, dentro de disciplinas relacionadas ao Cálculo, por possuir aplicações em várias áreas do conhecimento.
\end{abstract}

O interesse investigativo nesse tópico de Cálculo é plausível pela oportunidade que os conceitos de derivadas proporcionam para os estudantes desenvolverem habilidades matemáticas, essenciais ao sucesso na caminhada do estudo em tópicos avançados de matemática. Concernente ao conceito de derivadas, Gonçalves (2012, p. 32) afirma que:

\begin{abstract}
A derivada é um conceito que pode ser explorado a partir de diversos focos: derivada como um limite, como inclinação da reta tangente a uma curva em um ponto dado, além de situações que envolvam taxa de variação e máximos e mínimos.

Uma das possíveis causas para as dificuldades dos alunos na aprendizagem do conceito de derivada pode estar relacionada a dificuldades na compreensão do conceito de limite, que, por sua vez, ocasionam dificuldades na aplicação do conceito de derivada, em decorrência do fato da derivada ser um limite.
\end{abstract}

Para Maor (2008) a derivada está relacionada a mudanças, isto é, sua dimensão está ligada ao estudo das variações das taxas e o comportamento de fenômenos físicos relacionados com tempo, velocidade, aceleração, corrente elétrica fluindo em um circuito. O conceito de derivada está relacionado aestudo de funções em relação à taxa de variação instantânea que está presente em diversas situações do cotidiano por meio de diversas taxas como, - crescimento de uma determinada população, economia de um país, mortalidade infantil, variação de temperaturas, velocidade de corpos, ou seja, o estudo da variação de uma determinada função em momentos específicos.

De acordo com Igliori (2009) as constantes pesquisas em relação a esse tema buscam compreender as principais causas do baixo índice de aproveitamento da maioria dos discentes dos cursos da área de Ciências Exatas. Para o autor, os discentes dos cursos de graduação da área de Ciências Exatas apresentam dificuldades de aprendizagem nas disciplinas relacionadas a derivadas. De acordo com Reis (2009), um dos fatores que contribui para essa frustração, por parte dos alunos, é a metodologia utilizada pelo professor, isto é, as atividades são repetitivas e sempre desenvolvidas da mesma maneira: utilização do quadro para explicação e solicitação de resolução de longas listas de exercícios. Diante desta realidade, Catapani (2001) e Barbosa (2004) destacam que é fundamental incentivar as pesquisas neste tópico porque estas podem apontar causas e apresentar caminhos que contribuirão para superar as dificuldades de aprendizagem apresentadas pelos alunos.

D'Avoglio (2002) destaca que as dificuldades estão relacionadas com o entendimento da definição formal da derivada a partir do uso do conceito de limite. Além disso, o autor destaca que os discentes ainda não desenvolveram competências matemáticas essenciais para auxiliar na compreensão desse 
tema. O referido autor investigou sobre "Derivada de uma função num ponto: uma forma significativa de introduzir o conceito" e chegou à conclusão por meio do Teste de Sondagem (que foi aplicado em seis turmas de graduação para verificar a habilidade dos alunos em trabalhar com o aspecto conceitual de derivadas e não com a capacidade de manipular fórmulas) que os alunos confundem os seguintes conceitos:
a) derivada com reta tangente
b) derivada num ponto com a função derivada,
c) derivada com regra para se achar a derivada,
d) reta tangente com coeficiente angular da reta tangente e também, que muitos apresentam dificuldades de expressão (D'AVOGLIO, 2002, p. 2).

Partindo desses conceitos, salienta-se que o foco deste trabalho em relação ao ensino de Cálculo, foi apenas a exploração de derivadas envolvendo funções de uma variável, em particular, as aplicações de taxa de variação e mínimo. Concernente a estes temas citados, no âmbito das derivadas destaca-se que:

\begin{abstract}
Muitos fenômenos físicos envolvem grandezas que variam, como a velocidade de um foguete, a inflação de uma moeda, o número de bactérias em um a cultura, a intensidade do tremor de um terremoto, a voltagem de um sinal elétrico, a assim por diante... O estudo de taxas de variação está bastante relacionado com o conceito geométrico de uma reta tangente a uma curva. (ANTON; BIVENS; DAVIS, 2007, p. 165).
\end{abstract}

Partindo da abordagem dos autores citados, entende-se que o estudo de derivadas está relacionado à exploração do conceito de reta tangente. Desta forma, é relevante destacar o significado dessa palavra para instigar a reflexão acerca de seu papel no contexto de derivadas. Sendo assim, "[...] a palavra tangente vem do latim tangens, que significa tocando. Uma tangente a uma curva é uma reta que toca a curva. Em outros termos, uma reta tangente deve ter a mesma direção que a curva no ponto de contato [...]" (STEWART, 2013, p. 76). A figura 1 representa esta definição.

Figura 1 - Coeficiente angular da reta tangente em $\mathrm{P}$

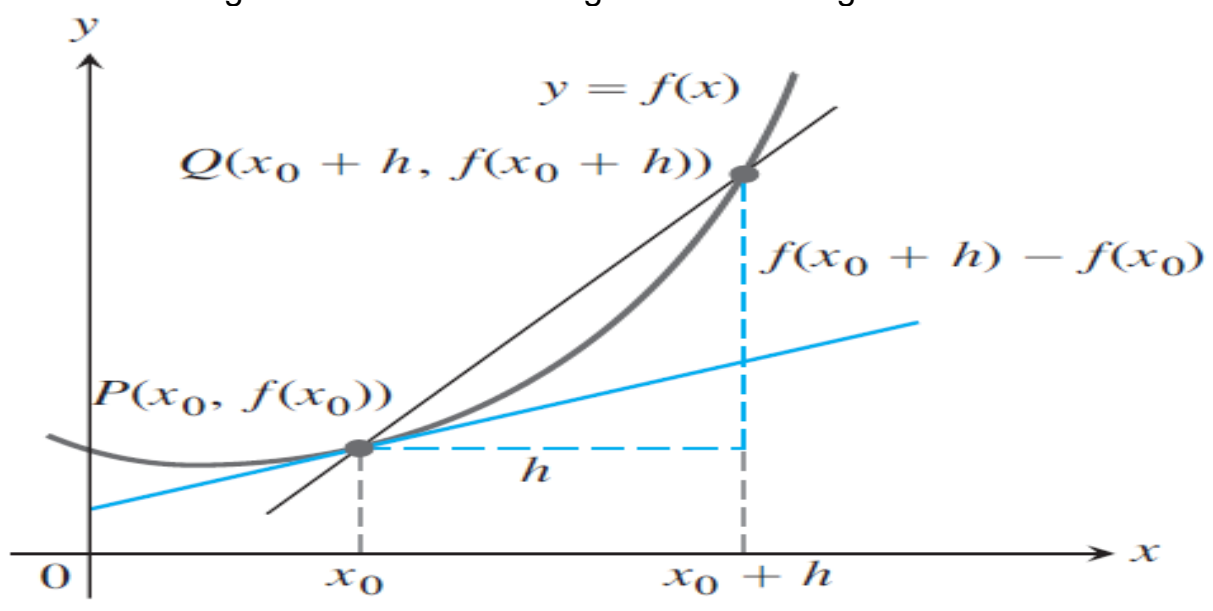

Fonte: Thomas, Weir e Hass (2012, p.117)

Thomas, Weir e Hass (2012) expressam a definição de coeficiente angular e reta tangente que os autores apresentam geometricamente na figura 1 . Dessa forma, para os autores o coeficiente angular da curva $y=f(x)$ no ponto $P\left(x_{0}, f\left(x_{0}\right)\right)$ é o número $m$ produzido pela existência do limite expresso por $m=$ 
$\lim _{h \rightarrow 0} \frac{f\left(x_{0}+h\right)-f\left(x_{0}\right)}{h}$. A reta tangente à curva em $\mathrm{P}$ é a que passa por $\mathrm{P}$ com esse coeficiente angular.

Diante desse contexto, optou-se por usar tarefas na perspectiva da investigação matemática, por acreditar que esta metodologia possibilita ao aluno ser ativo nos processos de ensino e aprendizagem. Na próxima seção, serão discutidas ideias dos autores que embasaram o uso desta metodologia na prática pedagógica efetivada.

\title{
Investigação Matemática
}

Ponte, Brocardo e Oliveira (2016) descrevem sobre os fundamentos da Investigação Matemática, bem como sobre a ação pedagógica dos professores e alunos nas aulas de Matemática em que é utilizada a metodologia. Analisam as contribuições do desenvolvimento de atividades envolvendo a Investigação Matemática nos processos de ensino e de aprendizagem desta área de conhecimento. Nessa perspectiva os autores destacam que:

\begin{abstract}
Importa saber se está ao alcance dos alunos investigar questões matemáticas e de que forma isso pode contribuir para a sua aprendizagem. Importa também saber de que competências necessitam os professores para promover esse tipo de trabalho nas suas aulas e que condições são necessárias para que isso aconteça. (PONTE; BROCARDO; OLIVEIRA, 2016, p. 9).
\end{abstract}

O reconhecimento das condições cognitivas dos educandos para a investigação matemática e as potencialidades para o desenvolvimento da aprendizagem são fundamentais à exploração do trabalho em sala de aula por meio de tarefas investigativas. Além disso, de acordo com os referidos autores, os professores precisam compreender que necessitam desenvolver algumas competências e refletir sobre que condições serão necessárias para a realização deste trabalho no seu âmbito escolar.

Segundo Ponte (2016), investigar não significa trabalhar com problemas complexos considerados difíceis, mas com a formulação de atividades sem respostas prontas, que instigue os alunos a formar conjecturas, construir conhecimentos com autonomia. Dessa forma, Ponte (2016) destaca que a Investigação Matemática é uma metodologia que dispõe de recursos capazes de incentivar a construção do conhecimento em tópicos tais como a geometria, os números e a estatística.

Diante da potencialidade que a Investigação Matemática vem demonstrando nos últimos anos, é importante ressaltar que:

Em numerosas experiências já empreendidas com trabalho
investigativo, os alunos têm mostrado realizar aprendizagens de
grande alcance e desenvolver um grande entusiasmo pela
Matemática. Apesar disso, não encaramos as investigações
matemáticas como a chave que permite por si só resolver todos os
problemas do ensino da Matemática. Há muitas outras atividades a
realizar na sala de aula. (PONTE; BROCARDO; OLIVEIRA, 2016, p.
$10-11$ ).

Contribuindo com a ideia desses autores, Gonçalves (2012) enfatiza que a Investigação Matemática instiga os professores a buscarem mudanças no 
cotidiano da sua ação pedagógica na sala de aula em prol da construção significativa do conhecimento, mediante a promoção da aprendizagem dos educandos. "Para isso, é necessário que o professor adote uma postura diferenciada em suas aulas, propondo atividades que sejam capazes de desenvolver nos alunos, habilidades diversas de modo que ocorra uma aprendizagem efetiva" (GONÇALVES, 2012, p. 39).

Diante desse contexto, a Investigação Matemática é uma oportunidade para o ensino de matemática. Segundo Menezes (2016, p. 10), as ações com caráter investigativo exploratório mobilizam a participação dos alunos nas aulas, visto que:

\begin{abstract}
Uma tendência contemporânea no ensino de matemática é o trabalho com atividades exploratórias, atividades com investigação. Essas atividades mobilizam os estudantes a participarem da aula construindo o conhecimento. $O$ professor deixa de ser a figura central, o "dono do conhecimento", e passa a ser um orientador. Vantagens significativas residem nesse tipo de aula: alunos interagem com objetivos comuns, na busca de determinados resultados, podem surgir outros também significativos, conjecturas são produzidas e testadas.
\end{abstract}

Analisando o pensamento do autor, o trabalho com tarefas investigativas é relevante porque promove a interação dos educandos com os objetos, que são propícios na construção dos resultados. Para o desenvolvimento de trabalhos em sala de aula por intermédio da Investigação Matemática, é fundamental que as tarefas investigativas estejam pautadas em quatro momentos. Tais momentos, de acordo com Ponte, Brocardo e Oliveira (2016) necessitam ser realizados para dar significado e possibilidade à construção do conhecimento com autonomia. Cada ação desses momentos está descrita no Quadro 1.

Quadro 1- Momentos na realização de uma investigação

\begin{tabular}{|l|l|}
\hline $\begin{array}{l}\text { Exploração e } \\
\text { formulação de } \\
\text { questões }\end{array}$ & : Explorar a situação-problema \\
\hline Conjecturas & : Formular questões \\
\hline $\begin{array}{l}\text { Testes e } \\
\text { reformulação }\end{array}$ & - - Rearmular conjecturar Refinar uma conjectura \\
\hline $\begin{array}{l}\text { Justificação e } \\
\text { avaliação }\end{array}$ & - Justificar uma conjectura \\
\hline
\end{tabular}

Fonte: Ponte, Brocardo e Oliveira (2016, p. 21).

Dessa forma, para Ponte, Brocardo e Oliveira (2016), a realização interativa desses quatro momentos é importante para a conquista de resultados satisfatórios. Diante dessa fundamentação é essencial a percepção de que:

O conceito de investigação matemática, como atividade de ensinoaprendizagem, ajuda a trazer para a sala o espírito da atividade matemática genuína, constituindo, por isso, uma poderosa metáfora educativa. O aluno é chamado a agir como um matemático, não só na formulação de questões e conjecturas e na realização de provas e refutações, mas também na apresentação de resultados e na discussão e argumentação com os seus colegas e o professor. (PONTE; BROCARDO; OLIVEIRA, 2016, p. 23).

Interagindo com a argumentação de outros autores (BACCARIN, 2008; PEREIRA; SCHMITT, 2015; MENEZES, 2016; e MACCALI, 2017; 
MAGALHÃES; VARIZO, 2016), verifica-se que o desenvolvimento de tarefas investigativas nas aulas de Matemática contribui para a construção coletiva de conhecimento, a partir da interação dos alunos entre si e com o professor, onde as etapas realizadas devem ser discutidas e argumentadas. $\mathrm{O}$ diferencial do trabalho com investigação matemática é a conexão mútua das etapas das atividades que ocorrem deste o reconhecimento do problema até a avaliação do resultado do raciocínio. É importante explicitar que o aluno tem a responsabilidade de demonstrar iniciativa na busca pela descoberta. Assim, os professores não devem apresentar respostas ou caminhos sobre a resolução das tarefas, e sim instigar os alunos para que estes elaborem suas conjecturas e estratégias de resolução.

Segundo Ponte, Brocardo e Oliveira (2016) sempre é possível organizar um cronograma de como ocorre o início de uma investigação, mas é improvável definir como ela termina. Não tem como prever os caminhos que os alunos irão usar, os conflitos entre eles, se precisam recomeçar, nem prever qual será o comportamento da turma diante das intervenções do professor, visto que:

\begin{abstract}
Em sala de aula, o professor tem papel essencial no planejamento da atividade investigativa. Além de definir a relevância dessa tarefa dentre as demais a serem realizadas pela turma, também decide com que frequência ela será recorrente. Após selecionar a situação a ser investigado, o docente deve iniciar o planejamento da aula. $\mathrm{Na}$ organização e gestão da aula, deve levar em conta tanto a natureza da atividade da investigação quanto os objetivos almejados. Nestas definições, deve considerar, em particular, o modo pelo qual os alunos realizarão o trabalho. (PEREIRA, 2015, p. 27).
\end{abstract}

Portanto, para Ponte, Brocardo e Oliveira (2016) o desenvolvimento de uma tarefa de investigação pode auxiliar o professor na sala de aula como um instrumento metodológico e instigar os alunos a buscar estratégias que favoreçam a aprendizagem.

\title{
Metodologia
}

A presente proposta foi fundamentada na pesquisa qualitativa porque "[...] pesquisas realizadas segundo uma abordagem qualitativa nos fornecem informações mais descritivas, que primam pelo significado dado às ações [...]" (BORBA; ARAÚJJO, 2017, p. 25). Além disso, observa-se que:

\begin{abstract}
As características da pesquisa qualitativa são: objetivação do fenômeno; hierarquização das ações de descrever, compreender, explicar, precisão das relações entre o global e o local em determinado fenômeno; observância das diferenças entre o mundo social e o mundo natural; respeito ao caráter interativo entre os objetivos buscados pelos investigadores, suas orientações teóricas e seus dados empíricos; busca de resultados os mais fidedignos possíveis. (GERHARDT; SILVEIRA, 2009, p. 32).
\end{abstract}

Borba e Araújo (2017) ainda contribuem com esta temática destacando que a pesquisa qualitativa deve estar pautada em uma visão de conhecimento que busque a otimização das informações a partir dos instrumentos de coleta de dados como observações, entrevistas, análises de vídeos, interpretações, etc. Assim, a presente pesquisa é qualitativa porque a pretensão foi compreender os comportamentos de um determinado grupo ao trabalharem com tarefas 
investigativas explorando assuntos relacionados ao tema derivadas. Além disso, foram analisadas as estratégias e conjecturas elaboradas por grupo de alunos no decorrer do desenvolvimento da tarefa investigativa, bem como a argumentação da forma de resolução na socialização dos resultados.

À luz dessa abordagem, a observação participante auxiliou o desenvolvimento dinâmico deste trabalho, visto que:

A observação participante é uma modalidade especial de observação na qual você não é apenas um observador passivo. Em vez disso, você pode assumir uma variedade de funções dentro de um estudo de caso e pode, de fato, participar dos eventos que estão sendo estudados. (YIN, 2001, p. 112).

Analisando a afirmação do autor, a observação participante proporcionou o contato constante e ativo com o grupo em estudo porque "[...] consiste na participação real do pesquisador com a comunidade ou grupo. Ele se incorpora ao grupo, confunde-se com ele. Fica tão próximo à comunidade quanto um membro do grupo que está estudando e participa das atividades normais deste [...]" (MARCONI; LAKATOS, p. 2019, p. 211). Esta atitude é importante porque o papel do professor pesquisador na Investigação Matemática é de mediador, ou seja, é o elemento-chave que deve auxiliar os alunos a compreenderem a essência de investigar, proporcionando o entendimento de todos os alunos acerca do sentido da tarefa proposta (PONTE; BROCARDO; OLIVEIRA, 2016).

A pesquisa tem características de estudo de caso, pois, o trabalho foi feito com uma única turma e o foco foi analisar por diferentes instrumentos de coleta de dados (resolução das atividades dos alunos e gravações dos diálogos dos grupos) os dados emergentes dessa turma para responder a questão de pesquisa. Nessa perspectiva, Lüdke e André (2018, p. 21) afirmam que estudo de caso é recomendado"[...] para compreender melhor manifestação geral de um problema, as ações, as percepções, os comportamentos e as interações das pessoas devem ser relacionadas à situação específica onde ocorrem [...]".

Assim, os dados também foram coletados mediante os seguintes instrumentos: caderno de campo/anotações (utilizado pelo professor/pesquisador e pelos alunos) e gravador de voz. Os alunos registraram durante as atividades, informações relevantes sobre os procedimentos adotados, destacando as conjecturas e conclusões estabelecidas sobre os conteúdos explorados no caderno de anotações que receberam. Cada grupo recebeu um caderno e elegeu um aluno, para fazer os registros, isto é, os resultados e os procedimentos utilizados para a elaboração de conjecturas em cada atividade. Souza (2013) destaca que esses instrumentos são fundamentais para o registro detalhado das informações e as reflexões dos resultados encontrados durante todo o processo da atividade desenvolvida.

O gravador de voz foi utilizado para coletar informações que poderiam ter escapado do registro dos cadernos do professor/pesquisador e dos alunos. Em cada grupo foi colocado um gravador para gravar as discussões durante o desenvolvimento da atividade, bem como foi gravada a socialização que ocorreu no final da tarefa. O uso deste instrumento de coleta de dados corrobora significativamente a reprodução fiel da veracidade dos resultados apresentados (MARCONI; LAKATOS, 2019). 
Os dados coletados foram analisados a partir da análise descritiva porque o foco foi descrever todos os fatos e dados de maneira mais real e verídica possível. Segundo Cervo et al (2007) esta análise possibilita a descrição detalhada das características e das relações existentes nos grupos, comunidades ou realidade analisada. Além disso, para esses autores este tipo de análise favorece a pesquisa de forma mais ampla e completa, pois se preocupa com a análise dos fatos, os quais devem ser descritos em detalhes, para então serem analisados à luz de referenciais teóricos consistentes.

A pesquisa foi desenvolvida na disciplina de Cálculo I, em uma turma de Licenciatura em Matemática, de uma instituição do Norte do Brasil, localizada no Estado do Amazonas. Foram desenvolvidas cinco tarefas investigativas em 2019 para 20 discentes, 15 homens e 5 mulheres, que cursavam o $2^{\circ}$ período do referido curso de graduação, mas neste artigo serão socializadas a análise de uma delas. Além disso, vale salientar que 8 desses alunos já cursaram esta disciplina anteriormente e não foram aprovados. Destaca-se que neste artigo, serão socializados os resultados da análise efetivada de apenas uma das tarefas exploradas com os alunos.

A turma foi dividida em cinco grupos de quatro discentes, pois é um dos princípios da investigação matemática o trabalho em grupo, pois para Ponte Brocardo e Oliveira (2016) a utilização do trabalho em equipe na sala de aula favorece a construção coletiva do conhecimento. Antes do início da prática pedagógica, foi realizada reunião com os alunos para explicação dos procedimentos da tarefa, discussão sobre as etapas da Investigação Matemática, e assinatura do Termo de Livre Consentimento e Esclarecido, concordando em participar da pesquisa. Devido a turma ser voltada para formação de professores foi importante refletir sobre a Investigação Matemática como um instrumento metodológico que pode auxiliar na atividade docente.

Essa atividade foi desenvolvida em dois momentos. No primeiro realizou-se a reunião citada com duração de duas horas-aula de 50 minutos. No segundo momento foi aplicada a tarefa investigativa apresentada no Quadro 2. Essa foi realizada em três aulas de 50 minutos cada uma, e apresentada aos grupos pelo professor de forma escrita. Em seguida, os grupos foram motivados para a realização da investigação da tarefa, que visou a elaboração de conjecturas, depois testá-las e validá-las. A discussão dos resultados foi desenvolvida por meio dos relatos dos discentes, onde apresentaram as conclusões encontradas e as estratégias utilizadas (PONTE; BROCARDO; OLIVEIRA, 2016).

Quadro 2 - Tarefa: minimizando custo

Uma empresa constrói caixa d'água de alvenarias retangulares com o comprimento de 4 metros e o volume de 9 metros cúbicos.

a) Explore situações, investigando de acordo com o enunciado as dimensões que representam o volume do tanque. Justifique.

b) Investigue as áreas das faces do tanque que satisfazem o enunciado e justifique sua resposta.

c) Se existe dimensões que minimizam o custo para a fabricação dos tanques, encontre-as e justifique sua resposta.

Fonte: dos autores (2019).

Para a organização dos registros de anotações das respostas dos grupos, foi utilizada uma letra maiúscula para identificar cada equipe, como por exemplo: Grupo A, Grupo B, Grupo C, .... Para os alunos, nos registros das gravações foi 
utilizada uma letra maiúscula indicando o grupo e um algarismo indicativo representando o componente da equipe, como por exemplo: Aluno A1, Aluno A2, ..., Aluno B1, Aluno B2, ..., Aluno C1, Aluno C2, ... Na próxima seção, serão apresentados e discutidos os dados emergentes da resolução da tarefa do quadro 2.

\section{Resultados emergentes da tarefa minimizando custo}

Diante da tarefa apresentada no Quadro 2, os cinco grupos começaram a investigar em busca de formular conjecturas de acordo com os itens propostos na atividade. Analisando as respostas apresentadas pelos grupos, quatro (grupos A, B, C e E) utilizaram a mesma estratégia para responder os três itens solicitados na atividade, isto é, atribuíram valores para a altura ou a largura de acordo com o volume de $9 \mathrm{~m}^{3}$ que deveria ter cada tanque retangular. $\mathrm{E}, \mathrm{o}$ grupo $D$, usou os conceitos de derivadas. A seguir as estratégias utilizadas pelos grupos para a resolução da tarefa.

O Grupo E, questionou se poderiam utilizar o notebook para explorar essa atividade no Excel, como destaca o diálogo abaixo:

\footnotetext{
Aluno E3: Professor, para esta atividade podemos utilizar o notebook para explorar as dimensões do tanque?

Professor: Por que vocês resolveram utilizar o notebook?

Aluno E3: É porque nós queremos utilizar o Excel para investigar as dimensões do tanque que deve ter o volume de $9 \mathrm{~m}^{3}$.

Aluno E1: É professor! Com o Excel os cálculos são mais rápidos.

Aluno E2: No Excel professor, dá também pra gente organizar em linhas e colunas as medidas das dimensões, o volume e a área total das faces do tanque.

Professor: Tudo bem.
}

A postura dos alunos acerca da escolha pela utilização de recursos tecnológicos corrobora com a afirmação de Borba, Silva e Gadanidis (2018, p. 59) quando apontam que a exploração desses recursos "oferecem caminhos propícios para processos como a formulação de conjecturas, realização de testes, refinamento de conjecturas, familiarização com notações, dentre outros".

A figura 2 destaca a construção produzida no Excel pelo Grupo E, onde são visualizadas as medidas da largura e da altura de acordo com o volume do tanque. De acordo com a produção do grupo, percebe-se que existem dimensões que minimizam o custo da produção de tanques, visto que o resultado destaca que existe uma área total mínima do tanque. 
Figura 2 - Construção de resposta do grupo E no Excel

\begin{tabular}{|c|c|c|c|c|c|c|c|}
\hline Largura & Altura & Comprimento & Volume & Área total do tanque & \multicolumn{3}{|c|}{ Área das faces do tanque } \\
\hline$x$ & $y$ & $z$ & $\mathrm{~V}$ & $2 x y+8 x+8 y$ & $2 x y$ & $8 x$ & $8 y$ \\
\hline 0,5 & 4,5 & 4 & 9 & 44,5 & 4,5 & 4 & 36 \\
\hline 1 & 2,25 & 4 & 9 & 30,5 & 4,5 & 8 & 18 \\
\hline 1,5 & 1,5 & 4 & 9 & 28,5 & 4,5 & 12 & 12 \\
\hline 2 & 1,125 & 4 & 9 & 29,5 & 4,5 & 16 & 9 \\
\hline 2,5 & 0,9 & 4 & 9 & 31,7 & 4,5 & 20 & 7,2 \\
\hline 3 & 0,75 & 4 & 9 & 34,5 & 4,5 & 24 & 6 \\
\hline 3,5 & 0,6429 & 4 & 9 & 37,64285714 & 4,5 & 28 & 5,1429 \\
\hline 4 & 0,5625 & 4 & 9 & 41 & 4,5 & 32 & 4,5 \\
\hline 4,5 & 0,5 & 4 & 9 & 44,5 & 4,5 & 36 & 4 \\
\hline 5 & 0,45 & 4 & 9 & 48,1 & 4,5 & 40 & 3,6 \\
\hline
\end{tabular}

Fonte: Alunos do Grupo E (2019)

Mediante a utilização da ferramenta tecnológica Excel, os alunos do grupo $\mathrm{E}$ construíram suas respostas e apresentaram suas conclusões como destaca as conversas gravadas.

Aluno E4: Como nós podemos organizar os dados da questão no Excel?

Aluno E2: Vamos escrever a equação do volume e isolar uma variável e encontrar a outra em função dos valores que vamos atribuindo.

Aluno E1: Como assim, não entendi?

Aluno E2: Vou explicar! Como o comprimento é $4 \mathrm{~m}$ e o volume é $9 \mathrm{~m}^{3}$, a gente pode montar uma equação para o volume mais ou menos assim: $x y 4=9$. Depois a gente isola o y e vai encontrando valores para ele de acordo com os valores de $\mathrm{x}$.

Aluno E1: Ah entendi! Então vai ficar $y=9 / 4 x$. Certo?

Aluno E2: Isso mesmo!

Aluno E3: Mas isso não é suficiente para responder as perguntas! Tem que ser volume e área.

Aluno E4: É verdade! Mas já sei como fazer.

Aluno E3: Como?

Aluno E4: Eu montei uma equação para a área total do tanque.

Aluno E3: Como assim?

Aluno E4: A soma das áreas das seis faces do tanque, e ficou assim: $A=2 x y+8 x+8 y$.

Aluno $\mathrm{E} 1$ : Pra que essa equação?

Aluno E4: É essa área que vai determinar o custo do tanque.

Aluno E3: É verdade, quanto maior a área total maior vai ser o custo para fabricar o tanque.

Aluno E2: Olha só pessoal! Depois de digitar alguns valores para $\mathrm{x}$, dá pra perceber que existe uma área total mínima quando os valores de $x$ e y se aproximam de 1,5, pois o Excel mostra que essa área é $28,5 \mathrm{~m}^{2}$.

A figura 2 e os diálogos citados explicitam que os alunos do grupo $\mathrm{E}$, a partir da utilização do Excel, chegaram à conclusão que o custo do tanque com as medidas citadas na atividade será o menor possível quando as medidas da largura e da altura forem iguais $1,5 \mathrm{~m}$, visto que, produzirá a menor área total das faces necessárias para a construção do tanque com $4 \mathrm{~m}$ de comprimento $\mathrm{e}$ volume de $9 \mathrm{~m}^{3}$. Portanto, o grupo $\mathrm{E}$ concluiu que existem dimensões mínimas que reproduzem um custo mínimo para a fabricação de tanques e a área total das faces do tanque se aproxima de $28,5 \mathrm{~m}^{2}$, que corresponde a mínima possível, já que para valores maiores ou menores de 1,5 m atribuídos a largura 
e a altura, a área total é maior que $28,5 \mathrm{~m}^{2}$. Essa conclusão está ilustrada na figura 2, que representa a estratégia construída pelo grupo $\mathrm{E}$ no Excel.

Dessa forma, percebeu-se vinculação com as ideias de Cardoso (2019) que destaca que a utilização de recursos tecnológicos nas aulas de Matemática pode trazer benefícios a aprendizagem dos discentes, pois para o autor, tais instrumentos promovem o interesse dos alunos e proporcionam a melhora de seu rendimento. Corroborando a autora, Santos e Amaral (2012, p. 84) explicam que "[...] a utilização de novas tecnologias alia-se à necessidade de se aprender melhor, de se utilizar recursos que promovam uma melhor aprendizagem [...]".

O grupo $\mathrm{C}$ apresentou simulações do cálculo da área total da caixa d'água sem considerar uma das faces, ou seja, sem a tampa. A seguir o diálogo, extraído das gravações do referido grupo, que confirma a ideia pensada pelo grupo.

Aluno C3: Para responder essa questão, penso que temos que calcular a área de cada face da caixa d'água.

Aluno C1: Por que a área?

Aluno C3: É porque como o tanque deve ser construído de alvenaria, a gente tem que descobrir quantos metros quadrados será necessário para construir essa caixa d'água, quanto mais metros quadrados, mais caro vai custar.

Aluno C4: Então nós temos que considerar seis faces?

Aluno C2: Acho que 5 faces, acho que a tampa não deve ser considerada porque a atividade não destaca se é com tampa ou sem tampa.

Aluno C3: Tudo bem! Vamos fazer os cálculos sem a tampa.

Em relação à decisão dos alunos do grupo $\mathrm{C}$ em calcular a área das faces da caixa d'água sem considerar a tampa, se deu porque em tarefas investigativas há possibilidades de mais respostas, desde que sejam justificadas. Para Magalhães e Varizo (2016, p. 37) isso acontece quando o professor desenvolve o papel de "[...] estimular o raciocínio matemático criativo do aluno, levando-o a utilizar o raciocínio indutivo e analógico, argumentar, fazer hipóteses e comprová-las".

A figura 3 destaca os cálculos efetuados pelo grupo $C$ para verificar o comportamento da área total da caixa d'água a partir das medidas estabelecidas pela atividade para o comprimento e o volume. 
Figura 3 - Simulações do grupo C

\begin{tabular}{|c|c|c|}
\hline & Volume & Soma das áreas \\
\hline $\begin{array}{ll}x= & y= \\
\frac{1}{4} & 9\end{array}$ & $\begin{aligned} 4 \cdot \frac{1}{4} \cdot 9 & =9 \mathrm{~m}^{3} \\
9 & =9\end{aligned}$ & $\begin{array}{ll}\left.S_{A}=(2 \cdot x \cdot y)+8 y+4 x\right) \mathrm{m}^{2} & S_{A}=4,5+72+1 \\
S_{A}=2 \cdot \frac{1}{4} \cdot 9+8 \cdot 9+4 \cdot \frac{1}{4} & \end{array}$ \\
\hline $\begin{array}{l}x=\frac{2}{4} \\
y=4,5\end{array}$ & $\begin{aligned} 4 \cdot \frac{2}{4} \cdot 4,5 & =9 \mathrm{~m}^{3} \\
9 & =9 \mathrm{~m}^{3}\end{aligned}$ & $\begin{array}{l}S A=12 \cdot \frac{2}{4} \cdot 4,5+8 \cdot 4,5+4 \cdot \frac{2}{4} \\
S A=4,5+36+2 \\
S A=42,5 \mathrm{~cm}^{2}\end{array}$ \\
\hline $\begin{array}{l}x=1,5 \\
y=1,5\end{array}$ & $\begin{array}{l}4.1 \cdot 5 \cdot 1 \cdot 5=9 \mathrm{~m}^{3} \\
9=9-\mathrm{m}^{3}\end{array}$ & $\begin{array}{l}S A=2 \times 1,5 \times 3.5+8 \times 1,5+4 \times 1,5 \\
S A=4,5+12+6 \\
S A=22,5 \mathrm{~cm}^{2}\end{array}$ \\
\hline $\begin{array}{l}x=1 \\
y=\frac{9}{4}\end{array}$ & $\begin{aligned} 2 \cdot 1 \cdot \frac{9}{4} & =9 \mathrm{~m}^{3} \\
9 & =9 \mathrm{~m}^{3}\end{aligned}$ & $\begin{array}{l}S_{A}=2 \times 1 \times \frac{9}{4}+8 \times \frac{9}{4}+4 \times 1 \\
S_{A}=4,5+18+4 \\
S A=26,5 \mathrm{~m}^{2}\end{array}$ \\
\hline $\begin{array}{l}x=2 \\
y=\frac{9}{8}\end{array}$ & $\begin{array}{l}4.2 \cdot \frac{9}{2}=9 \mathrm{~m}^{3} \\
9=9 \mathrm{~cm}^{2}\end{array}$ & $\begin{array}{l}S A=2 \times 2 \times \frac{9}{8}+8 \times \frac{9}{8}+4 \times 2 \\
S A=4,5+9+8 \\
S A=21,5 \mathrm{~m}^{2}\end{array}$ \\
\hline $\begin{array}{l}x=\frac{9}{8} \\
y=\frac{8}{4}\end{array}$ & $\begin{aligned} 4 \cdot \frac{9}{8} \cdot \frac{8}{4} & =9 m^{3} \\
9 & =9 m^{3}\end{aligned}$ & $\begin{array}{l}S_{A}=2 \times \frac{8}{4} \times \frac{9}{8}+8 \cdot \frac{9}{8}+4 \cdot \frac{8}{4} \\
S_{A}=4,5+9+8 \\
S_{A}=\quad 21,5 \mathrm{~m}^{2}\end{array}$ \\
\hline
\end{tabular}

Fonte: Alunos do Grupo C (2019).

De acordo com a figura 3, o grupo $\mathrm{C}$ descobriu que área total da caixa d'água se aproxima de um valor mínimo $\left(21,5 \mathrm{~m}^{2}\right)$ quando os valores da largura e altura se aproximam de $2 \mathrm{~m}$ e $\frac{9}{8} \mathrm{~m}$, respectivamente. Dessa forma, existem dimensões que proporcionam um custo mínimo para a construção da caixa d'água, visto que, se as medidas da largura e altura forem diferentes de $2 \mathrm{~m}$ e $\frac{9}{8}$ $\mathrm{m}$ a área total da superfície da caixa d'água vai ser maior e, então o custo para a construção vai aumentar. Em relação a utilização de apenas 5 faces e não 6 , o grupo descreve que discutiu sobre isso, mas que acabaram esquecendo de utilizar as seis faces. Só perceberam a questão das 6 faces no momento da socialização dos resultados, como pode ser observado no diálogo que segue:

Aluno C2: Precisamos encontrar a área de todas as faces para verificar as medidas ideais que diminuem o custo.

Aluno C1: Então, temos que utilizar 5 faces.

Aluno C4: Cinco? Por quê?

Aluno C1: Sim. O fundo, e as quatro paredes.

Aluno C4: E a tampa?

Aluno C1: Mas, é necessário utilizar também a tampa.

Aluno C3: Acho que sim. 
Aluno C1: Ok, então são seis faces.

Esse tipo de atividade é importante de ser explorada em sala de aula para evidenciar ao aluno que a investigação matemática auxilia na construção do conhecimento e na tomada de decisões no cotidiano. Este é um momento em que o professor deve incentivar os alunos a refletirem sobre o que produziram. Sobre este aspecto relacionado ao papel do professor, Ponte, Brocardo e Oliveira (2016, p. 53) explicam que "[...] é importante ajudá-los a fazer uma síntese da atividade, descrevendo os seus avanços e recuos, os objetivos que tinham em mente e as estratégias que seguiram".

Os grupos, A e B, utilizaram a mesma estratégia apresentada pelo grupo $\mathrm{C}$, ou seja, utilizaram apenas 5 faces e desenharam tabelas, desta forma, apresentálas seria repetir situações equivalentes. Mas, o grupo D, pontuou suas conclusões utilizando uma estratégia diferente, como observa-se no diálogo registrado abaixo:

Aluno D3: Olha só! Pelos testes que fizemos atribuindo valores para altura descobrimos que a área total das faces da caixa d'água se aproxima de um valor mínimo.

Aluno D1: Sim, mas o que você está pensando?

Aluno D3: Como os valores da área total mudam de acordo com as medidas que testamos, o que vocês acham se a gente utilizar derivadas para verificar essa ideia?

Aluno D4: Sim, concordo!

Aluno D1: Também concordo! Aí podemos confirmar se realmente existe dimensões para diminuir o custo da construção da caixa d'água.

Aluno D4: Isso mesmo irmão! Dá pra criar uma função para a área total da caixa d'água a partir da expressão do volume.

A figura 4 ilustra como os alunos do grupo D colocaram em prática o que discutiram no grupo. Desta forma, destacaram as medidas para a largura, altura, comprimento, volume e expressão para área total da caixa d'água de acordo com os dados enunciados na atividade proposta do Quadro 2. Assim, estabeleceram uma função para a área total relacionada com a expressão do volume. Depois, substituíram na expressão correspondente a área total e definiram assim uma função dependendo apenas da dimensão da largura denominada de $x$.

Figura 4 - Expressões matemáticas do volume e área total da caixa d'água

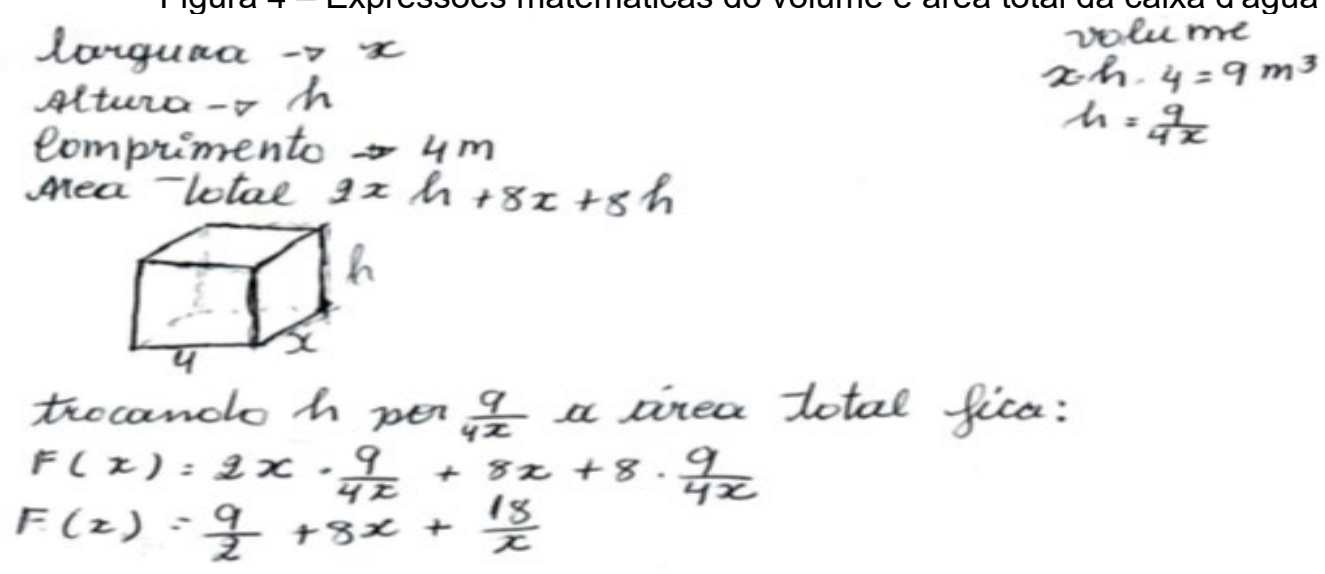

Fonte: Alunos do Grupo D (2019) 
Após a modelagem de uma função para a determinação da área total da superfície da caixa d'água, 0 grupo $D$ recorreu a ideia de derivada para explorar a existência de dimensões que minimizam o custo da construção da caixa d'água como ilustra a figura 5.

Figura 5 - Exploração de derivada pelo grupo D5

$$
\begin{aligned}
& \text { Derivando } F(x)=8-\frac{18}{x^{2}} \\
& \text { Logualoudo a zero, } \begin{array}{l}
0=8-\frac{18}{x^{2}} \\
\frac{18}{x^{2}}=8 \stackrel{8 x^{2}=18}{x^{2}}=\frac{18}{8} \\
x= \pm \sqrt{\frac{9}{4}} \\
x= \pm \frac{3}{2}
\end{array}
\end{aligned}
$$

Existe wirea total minima ola caixa N'ágera para $x=\frac{3}{2} \mathrm{~m}$ $F\left(\frac{3}{2}\right)=\frac{9}{2}+8 \cdot \frac{3}{2}+\frac{18}{\frac{3}{2}}$

$F\left(\frac{3}{2}\right)=\frac{9}{2}+12+12$

$F\left(\frac{3}{2}\right)=\frac{9}{2}+24=\frac{9+48}{2}=\frac{57}{2}=28,5 \mathrm{~m}^{2}$

Fonte: Alunos do Grupo D

O grupo $\mathrm{D}$ recorreu aos conceitos de derivadas para explorar a tarefa porque dois alunos, pertencentes à equipe, já tinham estudado a disciplina Cálculo I anteriormente. Dessa forma, compartilharam com os colegas algumas experiências que vivenciaram sobre as derivadas.

Segundo Stewart (2013) a utilização dos conceitos de derivadas é uma ferramenta importante em algumas aplicações do cálculo diferencial, visto que se refere a problemas de otimização. Assim, a partir da exploração de derivadas pode-se encontrar valores de máximo e mínimo que ajudarão na tomada de decisão. Nessa mesma linha de pensamento, Thomas, Weir e Hass (2012, p. 251) afirmam que podemos utilizar "[...] derivadas para resolver uma variedade de problemas de otimização nos negócios, matemática, física e economia". Portanto, a partir da utilização da Investigação Matemática, o grupo $\mathrm{D}$ estabeleceu relações matemáticas no âmbito de derivadas de acordo com definições estabelecidas pelos autores citados.

O grupo D, após os cálculos que estão representados na figura 5 , ainda realizou alguns testes de verificação dos valores encontrados, para confirmar suas conclusões, conforme visualizado na figura 6 .

Figura 6 - Testes de verificação das dimensões da caixa d'água

\begin{tabular}{c|c|c|c|c}
\hline largura & Altura & Comprimento & volume & frea total \\
\hline 1 & 2,25 & 4 & 9 & 30,5 \\
\hline 1,5 & 1,5 & 4 & 9 & 28,5 \\
\hline 2 & 1.125 & 4 & 9 & 29,5 \\
\hline
\end{tabular}

Fonte: Alunos do Grupo D (2019)

Conforme ilustra a figura 6 , o grupo D confirma a existência de dimensões que possibilitam uma área total mínima, ou seja, quando a altura e a largura se aproximam da medida de $1,5 \mathrm{~m}$ a área total se aproxima de um 
valor mínimo $\left(28,5 \mathrm{~m}^{2}\right)$. Dessa forma, o grupo $\mathrm{D}$ justificou que é possível construir a caixa d'água com o comprimento e volume desejado a partir da possibilidade de minimização de custo.

Depois do processo de investigação e discussão das conclusões realizadas em cada grupo, foram socializadas as resoluções. O representante escolhido pela equipe apresentou os resultados e o que fizeram para testá-los. Salienta-se que durante este processo, dos cinco grupos, três não consideraram uma face da caixa d'água, ou seja, consideraram um tanque sem tampa. Apenas os grupos $\mathrm{D}$ e $\mathrm{E}$ consideraram as seis faces e o $\mathrm{E}$ utilizou o Excel para investigar o comportamento da área total da caixa d'água de acordo com a variação da largura e da altura. Além disso, as equipes que não utilizaram as seis faces destacaram na apresentação final que não consideraram a tampa porque achavam que não havia necessidade, pois a questão não destacava se o tanque era ou não com tampa. Segundo Ponte, Brocardo e Oliveira (2016), o professor precisa estar atento a possibilidade de diversas respostas e como a questão não deixava explícito se era com tampa ou sem tampa significa que ambas as respostas estão corretas, pois os grupos justificaram porque encontraram tal resposta.

Vale destacar o entusiasmo dos alunos durante o desenvolvimento desta tarefa, como enfatiza os comentários abaixo:

Aluno A: A metodologia abordada é bastante interessante, e também não tivemos que partir de uma equação só, mas explorar os conhecimentos que temos para responder as questões.

Aluno D: Sim, porque quanto mais você investiga, descobre padrões matemáticos que ajuda a formular conjecturas.

Aluno B: Achei interessante porque, durante as investigações que fomos fazendo, percebemos o que ia acontecendo e com isso aprendemos diversos conceitos matemáticos.

Aluno C: Sim, porque nos motivou a pensar em diferentes formas até achar a melhor solução para as questões.

Aluno E: Foi bastante gratificante, pois presenciei o desenvolvimento de derivadas de outra forma, compartilhando os meus conhecimentos com os dos colegas através do trabalho em grupo.

Aluno D: Sim, porque às vezes nos prendemos a fórmulas matemáticas, e essa metodologia nos deu ideias diferentes, nos motivando a pensar em possibilidades a partir do raciocínio lógico.

O entusiasmo demonstrado pelos alunos durante a realização da tarefa aponta que a metodologia da investigação matemática tem potencial para auxiliar nos processos de ensino e de aprendizagem de matemática. Gonçalves (2012, p. 104) confirma essa possibilidade ao afirmar que:

[...] a realização das atividades investigativas contribuiu para uma ressignificação dos conhecimentos dos alunos, inicialmente construídos em sala de aula, a partir da oportunidade que eles tiveram de repensar/refletir sobre os conceitos envolvidos nas diversas aplicações das derivadas abordadas nas atividades.

Os grupos discutiram, buscaram alternativas para encontrar relações matemáticas de acordo com a tarefa proposta, formulando conjecturas e debatendo o significado das mesmas, traduz que trabalhar com tarefas investigativas pode contribuir com o desenvolvimento da aprendizagem matemática de forma dinâmica e eficaz. 


\section{Conclusão}

O presente trabalho foi realizado com o objetivo de analisar estratégias e conjecturas elaboradas pelos alunos da disciplina de Cálculo I, do curso de Licenciatura em Matemática, ao utilizarem tarefas investigativas envolvendo derivadas. O desenvolvimento da tarefa investigativa em sala de aula, demonstrou que a utilização da metodologia Investigação Matemática proporciona a construção de conhecimentos matemáticos fundamentados na interação do professor com os alunos.

Nessa perspectiva, essa construção de conhecimentos corrobora a proposta defendida por Ponte, Brocardo e Oliveira (2016) em considerarem que o desenvolvimento de tarefas investigativas em sala de aula é uma estratégia metodológica que pode auxiliar tanto o professor no ato de ensinar, quanto o aluno no seu processo de aprendizagem, visto que, é uma tendência de educação matemática que valoriza a iniciativa e criatividade dos alunos.

Durante a exploração da tarefa, os alunos manifestaram mudanças relacionadas com a motivação, interesse e compromisso na busca da construção de conhecimentos matemáticos, com autonomia. Além disso, a partir da observação constante dos grupos, os alunos demonstraram atitude de buscar estratégias no estabelecimento de relações matemáticas que favoreceu a melhoria no desempenho dos aspectos cognitivos.

Os resultados destacam indícios de que houve construção do conhecimento em relação ao tema derivadas, em particular no âmbito de taxa de variação e mínimo de funções. As aplicações de derivadas exploradas, como no exemplo da minimização de custo da construção de caixa d'água, possibilitaram fomentar a tomada de decisão, pois tiveram que decidir os resultados para a situação proposta, em grupo. Isto ocorreu porque segundo Gonçalves (2012), explorar aplicações de derivadas sob o olhar da investigação matemática favorece a autonomia dos alunos nas ações de formular, testar e validar conjecturas.

Em relação ao objetivo deste trabalho que foi analisar estratégias e conjecturas que os alunos da disciplina de Cálculo I, de uma turma de Licenciatura em Matemática, elaboram ao utilizarem tarefas investigativas envolvendo derivadas, pode-se inferir que os alunos utilizaram simulações, quadros, modelos matemáticos e o Excel para formularem conjecturas relacionadas com os conceitos de derivada, em particular com as ideias de mínimo de uma função. Os alunos utilizaram registros de suas resoluções por meio de representações simbólica e numérica. Em relação às conjecturas, formularam e testaram respostas usando caixas com cinco e seis faces. Ademais, houve evidências do uso de taxa de variação para o cálculo do valor mínimo (nesse caso, área total da caixa d'água) quando as dimensões (largura e altura) tendem para o mesmo valor que apontam para a validação da existência de dimensões que minimizam o custo da construção da caixa d'água.

Por fim, pode-se inferir que os resultados apresentados fundamentam que a metodologia de Investigação Matemática tem potencial para contribuir com os processos de ensino de matemática em sala de aula. Ademais, o auxílio de tecnologias possibilita aperfeiçoar os conhecimentos acumulados pelos alunos 
na caminhada escolar, instigando-os a construírem novos conceitos matemáticos indispensáveis à formação educacional e profissional.

\section{Referências}

ANTON, H.;. BIVENS, I.; DAVIS, S. Cálculo. Tradução: Claus Ivo Doering. $8^{a}$. Ed. Porto Alegre: Bookman, 2007.

BACCARIN, S. A. de O. Investigação matemática: uma análise da sua contribuição na construção de conceitos algébricos. 2008. 145 f. Dissertação (Mestrado em Educação) - Universidade de Brasília, Brasília, 2008.

BARBOSA, M. A. O insucesso no ensino e aprendizagem na disciplina de Cálculo Diferencial e Integral. 2004. 101 f. Dissertação de Mestrado em Educação. Pontifícia Universidade Católica do Paraná. Curitiba, 2004.

BORBA, M. de C.; ARAÚJO, J. de L.. Pesquisa Qualitativa em Educação Matemática. 5. ed. Belo Horizonte: Autêntica Editora, 2017.

BORBA, M. de C.; SILVA, R. S. R. da.; GADANIDIS, G. Fases das tecnologias digitais em educação matemática: sala de aula e internet em movimento. 2. ed.; 2. reimp. Belo Horizonte: Autêntica Editora, 2018.

BRASIL. MEC. Parâmetros curriculares nacionais para o Ensino Médio Ciências da Natureza, Matemática e suas Tecnologias. Secretaria de Educação Básica. - Brasília: MEC/SEF, 1998. Disponível em: http://portal.mec.gov.br/seb/arquivos/pdf/ciencian.pdf. Acesso em: 17 set. 2019.

Secretaria da Educação Fundamental. Parâmetros Curriculares Nacionais: Matemática. Brasília: MEC/SEF, 1998.

Ministério da Educação. Base Nacional Comum Curricular - BNCC. Brasília, DF, 2018. Disponível em: http://basenacionalcomum.mec.gov.br/wpcontent/uploads/2018/02/bncc-20dez-site.pdf. Acesso em: 30 nov. 2019.

CARDOSO, M. B. Práticas docentes e tecnológicas no ensino de matemática. Curitiba: CRV, 2019.

CATAPANI, E. C. Cálculo em serviço: um estudo exploratório. In: Bolema, Rio Claro, ano 14, n 16, p. 48-62, 2001.

CERVO, A. L. et al. Metodologia científica. 6 ed. São Paulo: Pearson Prentice Hall, 2007.

D'AVOGLIO, A. R. Derivada de uma função num ponto: uma forma significativa de introduzir o conceito. Dissertação de Mestrado em Educação Matemática. Pontifícia Universidade Católica de São Paulo. São Paulo, 2002.

GERHARDT, T. E.; SILVEIRA, D. T. Métodos de pesquisa. Porto Alegre: Editora da UFRGS, 2009.

GONÇALVES, D. C. "Aplicações das Derivadas no Cálculo I: Atividades Investigativas utilizando o GeoGebra"' 01/05/2012 110 f. Profissionalizante em EDUCAÇÃO MATEMÁTICA Instituição de Ensino: UNIVERSIDADE FEDERAL DE OURO PRETO, OURO PRETO Biblioteca Depositária: ICEB/UFOP, 2012. 
IGLIORI, S. B. C. Considerações sobre o ensino de Cálculo e um estudo sobre números reais. In: FROTA, M. C. R.; NASSER, L. (Org.). Educação Matemática no Ensino Superior: pesquisas e debates. Recife: SBEM, 2009. p.11-26.

KRUEGER, S. D. Matemática Significativa. Centro Universitário Leonardo da Vinci - Indaial: Grupo UNIASSELVI, 2009.

LAKATOS, E. M.; MARCONI, M. de A. Fundamentos de Metodologia Científica. 8. ed. São Paulo: Editora Atlas, 2019.

LÜDKE. M.; ANDRÉ, M. E. D. A. Pesquisa em educação: abordagens qualitativas. 2. ed. Rio de Janeiro: E. P. U., 2018.

MACCALI, L. Atividades Investigativas para o ensino da álgebra em turmas de $7^{\circ}$ ano e $9^{\circ}$ ano do Ensino Fundamental 2017. $116 \mathrm{f}$. Dissertação (Mestrado em Ensino de Ciências Exatas) - Centro Universitário UNIVATES, Lajeado, 2017.

MAGALHÃES, A. P. A. S.; VARIZO, Z. da C. M. Atividades Investigativas como uma estratégia de ensino e aprendizagem da matemática. Curitiba: CRV, 2016.

MAOR, E. e: a história de um número. Tradução de Jorge Calife. 4. ed. Rio de Janeiro: Record, 2008.

MENEZES, P. V. S. Métodos de contagem: uma abordagem investigativa. 2016. 77 f. Dissertação. Programa de Mestrado Profissional em Matemática em Rede Nacional - Universidade Federal de Sergipe. Itabaiana,

PEREIRA, A. B. L. Investigação Matemática: possibilidade para ensino de trigonometria 2015. 150 f. Dissertação (Mestrado em Ensino de Ciências Exatas) - Centro Universitário UNIVATES, Lajeado, 2015.

PONTE, J. P.; BROCADO, J.; OLIVEIRA, H. Investigações Matemáticas na Sala de Aula. 3 ed. rev. ampl; reimp. Belo Horizonte: Autêntica Editora, 2016.

REIS, F. S. Rigor e intuição no ensino de Cálculo e Análise. In: FROTA, M. C. R.; NASSER, L. (Orgs.). Educação Matemática no Ensino Superior: pesquisas e debates. Recife: SBEM, p. 81-97, 2009.

SANTOS, M. E. K. L. dos.; AMARAL, L. H. Avaliação de objetos virtuais de aprendizagem no ensino de matemática. Revista de Ensino de Ciências e Matemática. V. 3, n. 2, p. 83-93, 2012.

SANTOS, V. de M. A matemática escolar, o aluno e o professor: paradoxos aparentes e polarizações em discussão. Cad. Cades, Campinas, vol.28, n.74, p. 25-38, abr. 2008.

SCHMITT, F. E. Abordando Geometria por meio da investigação matemática: um comparativo entre $05^{\circ}$ e $9^{\circ}$ anos do ensino fundamental. 2015. 105 f. Dissertação (Mestrado em Ensino de Ciências Exatas) - Centro Universitário UNIVATES, Lajeado, 2015.

SOUZA, D. I. de. et al. Manual de orientações para projetos de pesquisa. Novo Hamburgo: FESLSVC, 2013.

STEWART, J. Cálculo. [tradução EZ2 Translate]. São Paulo: Cengage Learning, 2013. 
THOMAS, G. B.; WEIR, M. D.; HASS, J. Cálculo. Tradução Kleber Pedroso e Regina Simille de Macedo. 12. ed. - São Paulo: Pearson Education do Brasil, 2012.

YIN, R. K. Estudo de caso: planejamento e métodos. 4. ed. Porto Alegre: Bookman, 2001.

Recebido: $28 / 02 / 20$

Aprovado: $20 / 05 / 20$

Como citar: SOARES, C. J. F.; QUARTIERI, M. T. Tarefa Investigativa no ensino de derivadas em uma turma de Licenciatura em Matemática. Revista de Estudos e Pesquisa sobre Ensino Tecnológico (EDUCITEC), v. 6, e109620, 2020.

Direito autoral: Este artigo está licenciado sob os termos da Licença Creative CommonsAtribuição 4.0 Internacional. 